\title{
Integration of IR-UWB Services into Single- and Multi-Channel Optical Coherent OFDM Network
}

\author{
J. E. KADUM, R. S. FYATH \\ M.Sc Researcher, College of Engineering, Alnahrain University, Baghdad, Iraq \\ jaffar.emad@yahoo.com \\ Professor, College of Engineering, Alnahrain University, Baghdad, Iraq \\ rsfyath@yahoo.com
}

\begin{abstract}
Distribution of wireless communication signals over implemented optical networks is a challenged task since the presence of wireless services may affect the performance of the existing wired ones. This paper addresses the possibility of integrating impulse radio-ultrawideband (IR-UWB) wireless services into implemented coherent optical orthogonal frequency division multiplexing (CO-OFDM) network. Simulation results are presented for the transmission of a $625 \mathrm{Mb} / \mathrm{s}$ UWB signal with either $50 \mathrm{~Gb} / \mathrm{s}$ single-channel or three-channel OFDM system. Both Gaussian monocycle and $5^{\text {th }}$-order derivative Gaussian pulses are used to implement the UWB system with two modulation formats, namely ON-OFF keying (OOK) and biphase modulation (BPM). The simulation results reveal that the performance of the CO-OFDM channels is not affected in the presence of UWB signals.
\end{abstract}

\section{Indexing terms/Keywords}

IR-UWB-over-Fiber; CO-OFDM

\section{Academic Discipline And Sub-Disciplines}

Optical Communications

\section{SUBJECT CLASSIFICATION}

UWB-over-Fiber

\section{TYPE (METHOD/APPROACH)}

Simulation

\section{Council for Innovative Research}

\section{Peer Review Research Publishing System}

\section{Journal: INTERNATIONAL JOURNAL OF COMPUTERS \& TECHNOLOGY}

Vol. 14, No. 2

www.ijctonline.com , editorijctonline@gmail.com 


\section{1- INTRODUCTION}

Impulse radio-ultrawideband (IR-UWB) signals are considered the most promising schemes for next generation short-rang broadband wireless communication and sensor networks [1,2]. The Federal Communication Commission (FCC) limits the power spectral density (PSD) of a UWB signal to $-41 \mathrm{dBm} / \mathrm{MHz}$ over the spectral range 3.1-10.6 GHz. The low emitted PSD causes the wireless transmission distances to be limited within a few meters [3]. In this context, UWB-over-fiber (UWBoF) attracts increasing interest as a promising technology for extending the coverage of UWB services [4-5]. Further, several proposals have been reported in the literature to integrate UWB services into wavelength division multiplexing-passive optical network (WDM-PON) to provide high order data-rate and flexible wired and wireless services with a favorable cost [6-8].

The quest for higher spectral efficiency over long-haul fiber transmission has been studied intensively due to the exponential growth of global communications traffic [9]. Advanced signal processing and high-order modulation formats are the key technology to increase the spectral efficiency in these advanced optical communication systems [10,11] Recently, optical orthogonal frequency division multiplexing (O-OFDM) has opened up to high-order modulation formats and sophisticated modulation schemes for long-haul optical communication systems [12,13]. In fact, coherent optical (CO) OFDM is considered as promising candidate for future long-haul high capacity transmission systems [14,15]. This is mainly due to its high spectral efficiency and advantages in overcoming transmission impairments such as chromatic dispersion and polarization-mode dispersion [16].

The aim of this paper is to present a feasibility study for integrating IR-UWB wireless services with implemented COOFDM network. Simulation results are reported for transmitting $625 \mathrm{Mb} / \mathrm{s}$ Gaussian monocycle and $5^{\text {th }}$-order derivative Gaussian UWB signals with either single or three-channel CO-OFDM signals ( $50 \mathrm{~Gb} / \mathrm{s}$ per channel). The target is to trace the interfering effect between the wireless and wired services. The simulation results are obtained using commercia software package, Optisystem (version 13.0).

\section{2- CO-OFDM FIBER TRANSMISSION LINK}

The transmission link of the single-channel CO-OFDM system is illustrated in Fig. 1. The system is simulated using 50 $\mathrm{Gb} / \mathrm{s}$ QPSK signaling. Other parameter values used in the simulation are listed in Table 1.

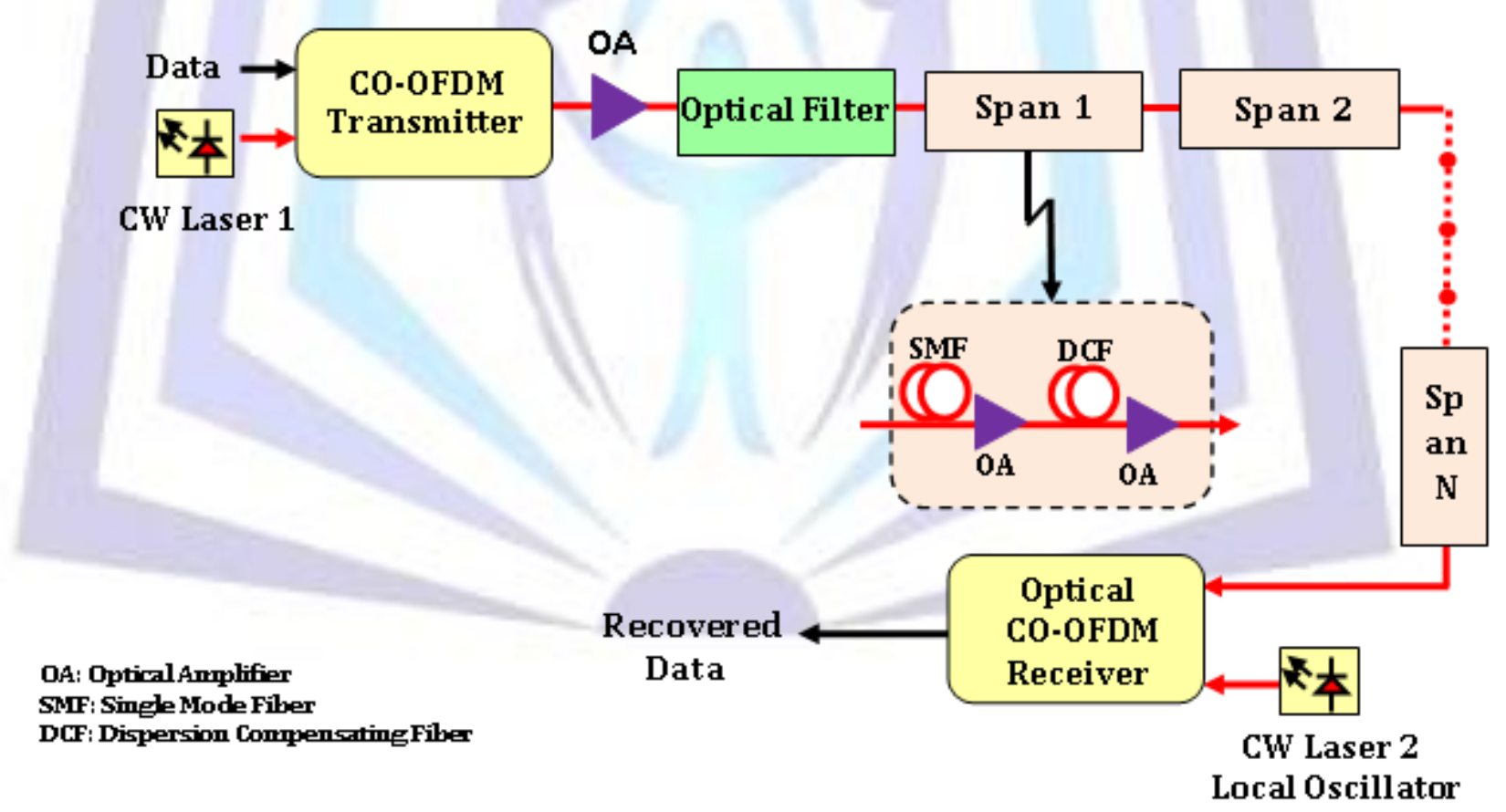

Fig. 1: Block diagram of the transmission link of CO-OFDM system.

The transmission link consists of number of spans; each span with $80 \mathrm{~km}$ single-mode fiber (SMF) and $16 \mathrm{~km}$ dispersion compensating fiber (DCF) along with their optical amplifiers (16 and $8 \mathrm{~dB}$ ). The average group velocity dispersion (GVD) and losses over the span is equal to zero. 
Table 1: Parameter values used for simulation $50 \mathrm{~Gb} / \mathrm{s}$ QPSK CO-OFDM.

\begin{tabular}{c|c}
\hline \hline Parameter & Value \\
\hline \hline Number of subcarriers, $N$ & 128 \\
\hline Number of FFT point & 256 \\
\hline Transmitter laser power & $-4 \mathrm{dBm}$ \\
\hline Transmitter laser wavelength, $\lambda$ & $1552.524 \mathrm{~nm}$ \\
\hline Booster amplifier gain & $10 \mathrm{~dB}$ \\
\hline Optical filter bandwidth & $40 \mathrm{GHz}$ \\
\hline Local oscillator laser power & $0 \mathrm{dBm}$ \\
\hline Local oscillator laser wavelength, $\lambda$ & $1552.524 \mathrm{~nm}$ \\
\hline \hline
\end{tabular}

The variation of BER with the number of spans is illustrated if Fig. 2 and given here for reference purposes. The received constellation diagrams after $0,1,12$ and 15 spans are given in Fig. 3 . The corresponding BERs at these distances are $0,6.2 \times 10^{-19}, 3.5 \times 10^{-16}$ and $1.1 \times 10^{-8}$, respectively. The simulation results reveal that CO-OFDM system under investigation can offer a received a BER less than $10^{-9}$ when the length of the transmission link is less than $1344 \mathrm{~km}$.

\section{Total length (km)}

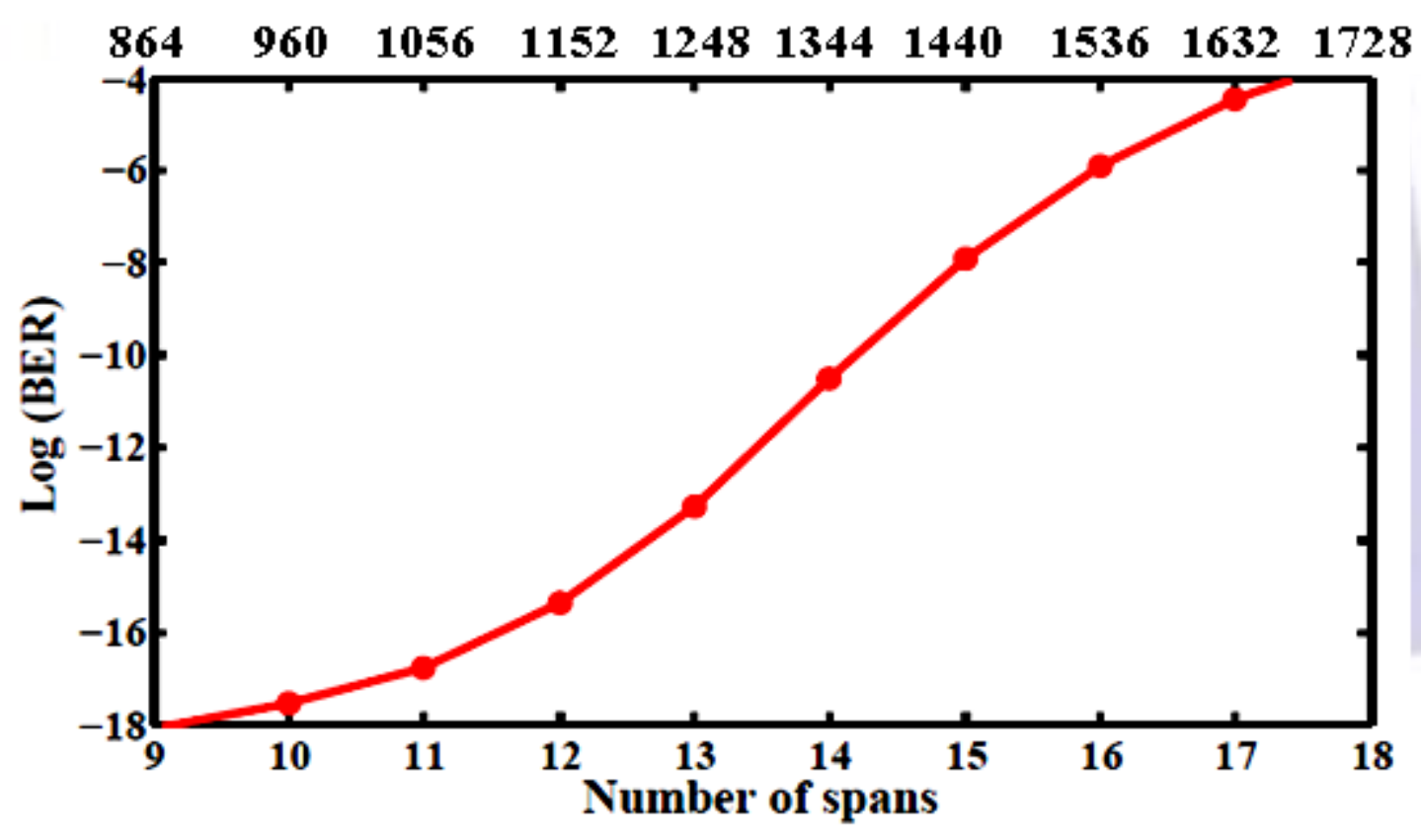

Fig. 2: BER as a function of number of spans and total link length for a single-channel OFDM system. 


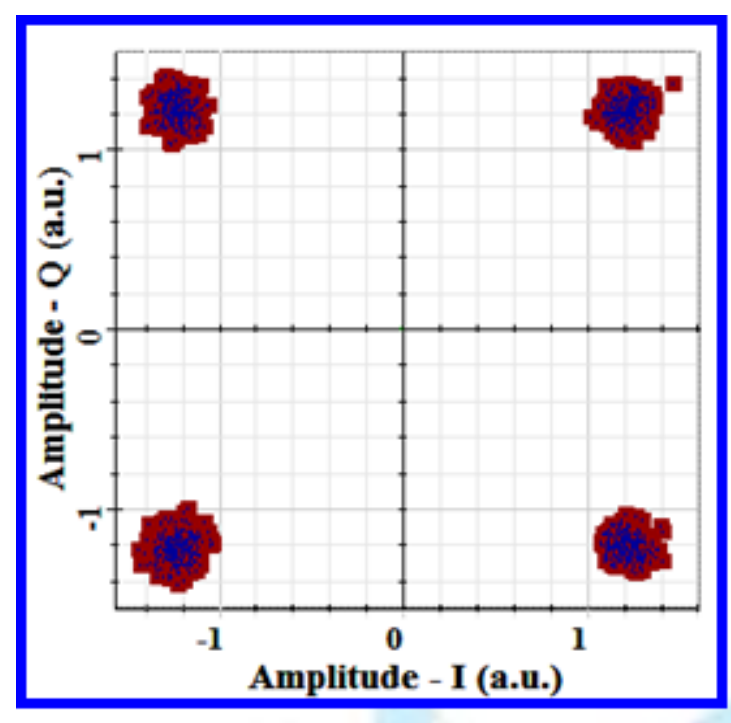

(a)

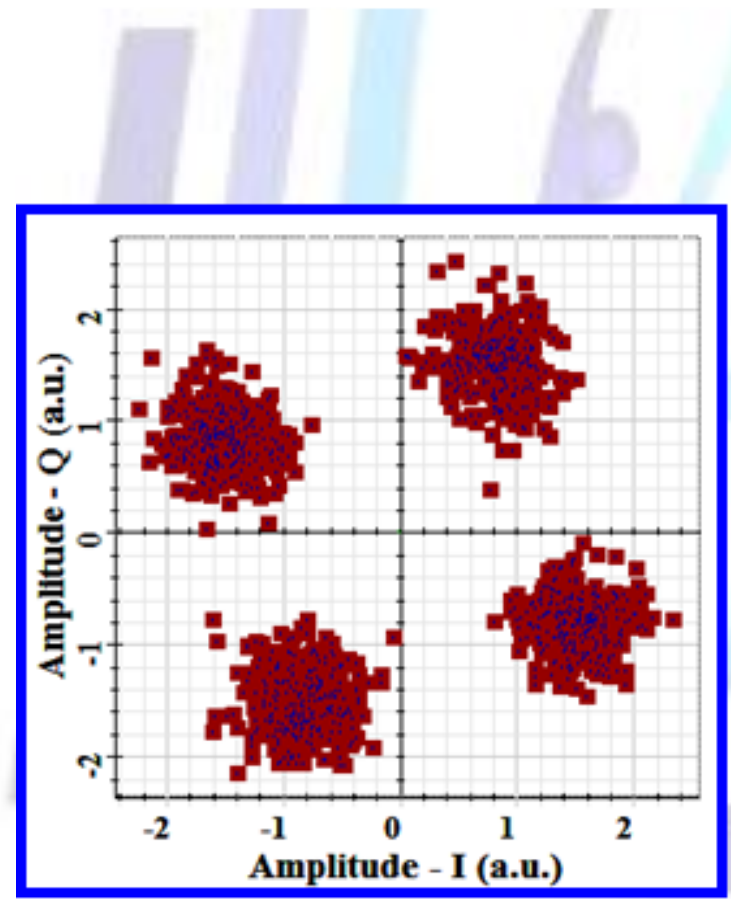

(c)

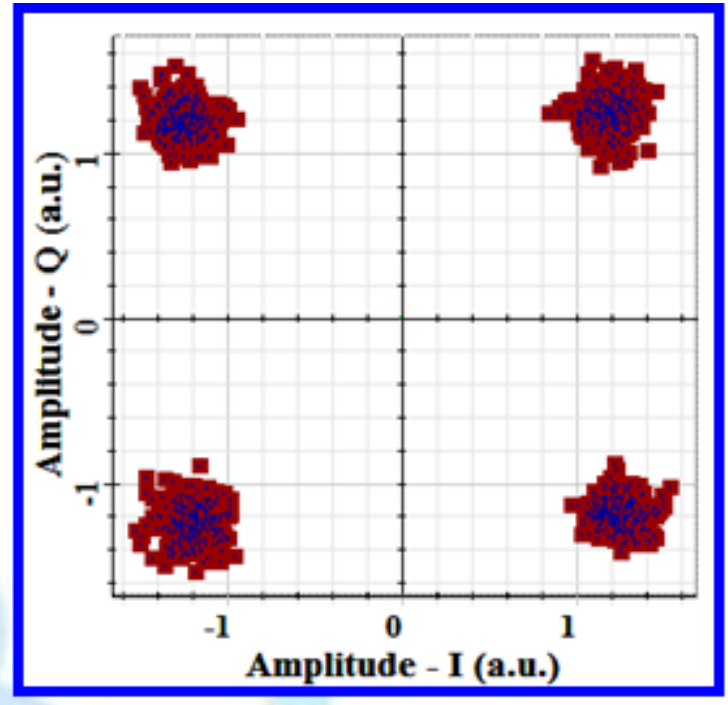

(b)

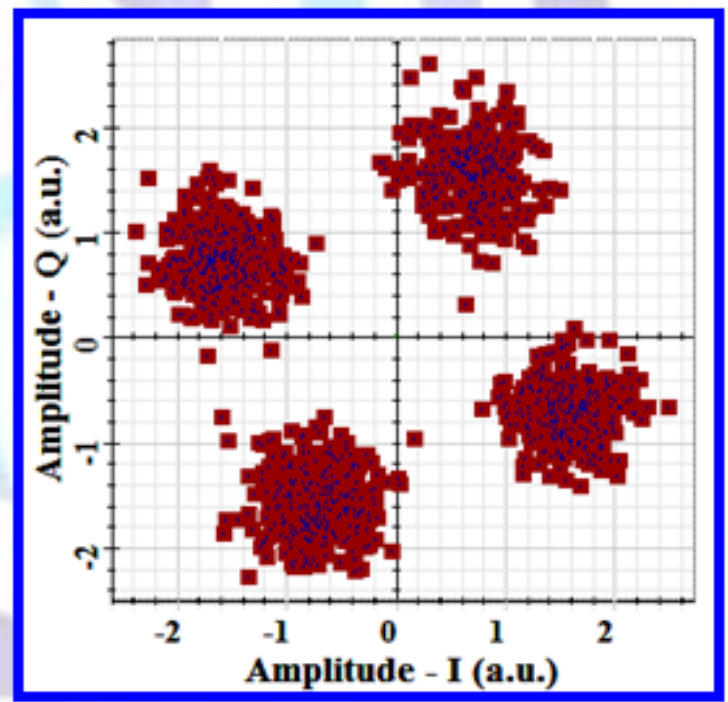

(d)

Fig. 3: Constellation diagrams of the received CO-OFDM signal after transmission over (a) back-to-back (b) one span (c) 12 spans (d) 15 spans. 


\section{3- Multiplexing IR-UWB Signal with a Single-Channel CO-OFDM System}

The starting point is to simulate the transmission of UWB signal with single-channel CO-OFDM. The system under investigation is illustrated schematically in Fig. 4. At the transmitter side, the UWB signal is multiplexed with the optical CO-OFDM signal and the resultant multiplexed signal is launched into the multi span optical link. A drop demultiplexer is inserted after the first span to drop the UWB signal. Simulation results are presented for $50 \mathrm{GHz}$ channel spacing with laser wavelengths $\lambda_{\mathrm{OFDM}}=1552.524 \mathrm{~nm}(193.1 \mathrm{GHz}), \lambda_{\mathrm{UWB}}=1552.122 \mathrm{~nm}(193.15 \mathrm{GHz})$.

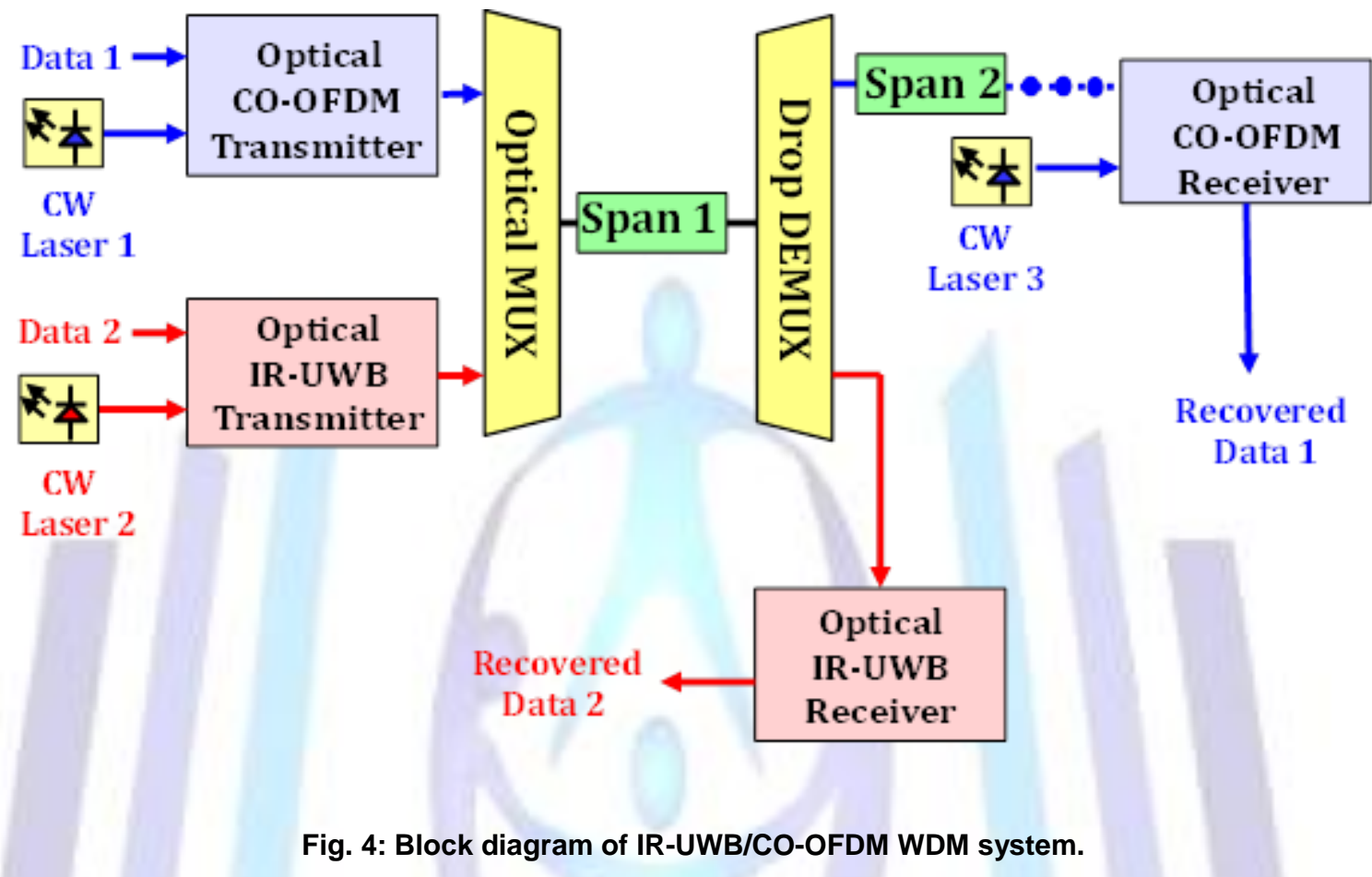

Figures 5a-d show the spectrum of the multiplexed signal corresponding to the four UWB signals (monocycle OOK, monocycle BPM, $5^{\text {th }}$-order derivative Gaussian OOK and $5^{\text {th }}$-order derivative Gaussian BPM), respectively. Investigating this figure reveals that there is a frequency guard between the UWB and OFDM spectrum. This enables the drop demultiplexer to recover safely the UWB signal without affecting the OFDM signal. The bandwidth of the OFDM is approximately $25 \mathrm{GHz}$ corresponds to double sideband of the spectrum of the RF-OFDM (electrical)

$(B W)_{\text {Co-OFDM }}=2(B W)_{R F-O F D M}=2\left[0.5 \times \frac{\text { Bit rate }}{\text { QPSN spectral efficiency }}\right]$

where the factor 0.5 introduced to take into account the effect of overlapping introduced by OFDM technique.

The transmission performance of the two-channel WDM system is simulated when the OFDM signal is multiplexed with each one of the four UWB signals. The results reveal that the presence of OFDM signal affects slightly the transmission performance of the UWB signals. In contrast, the transmission of UWB signal over the link will not affect the transmission performance of the CO-OFDM system. 


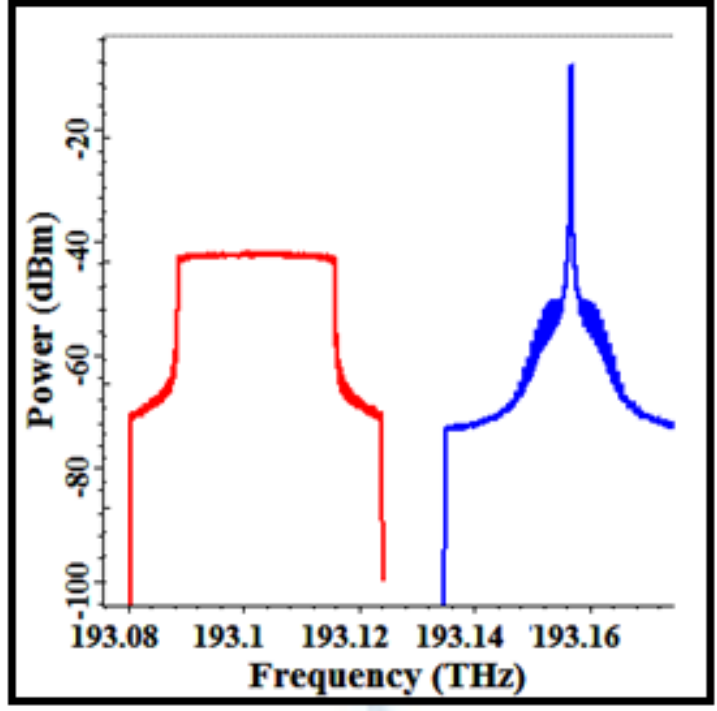

(a)

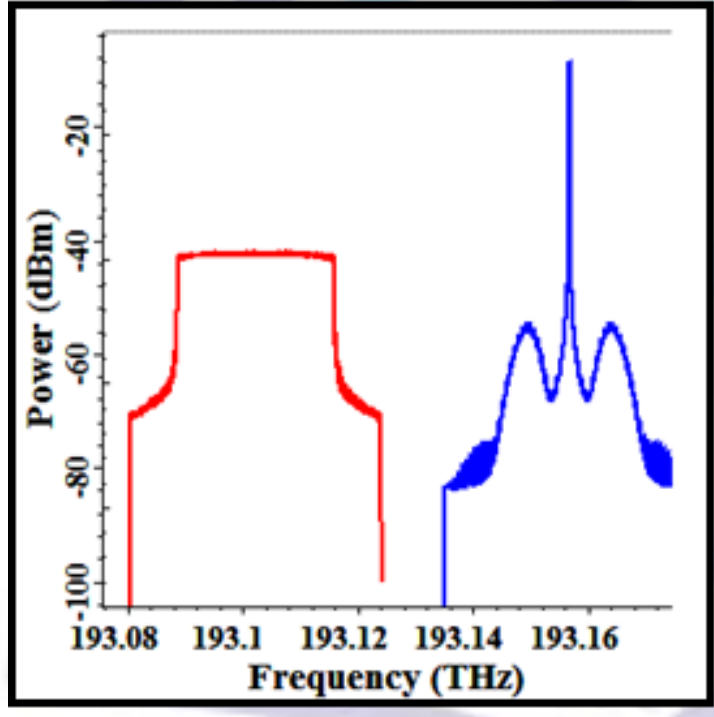

(c)

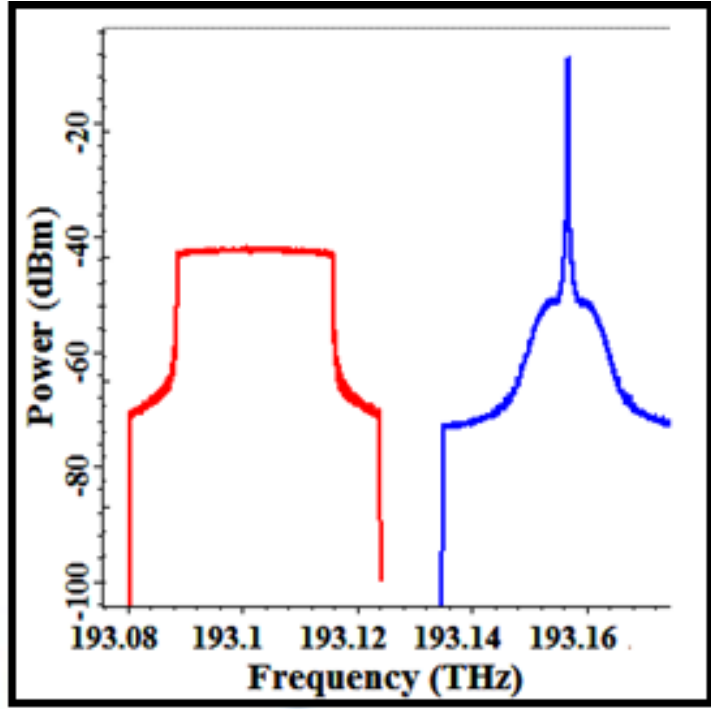

(b)

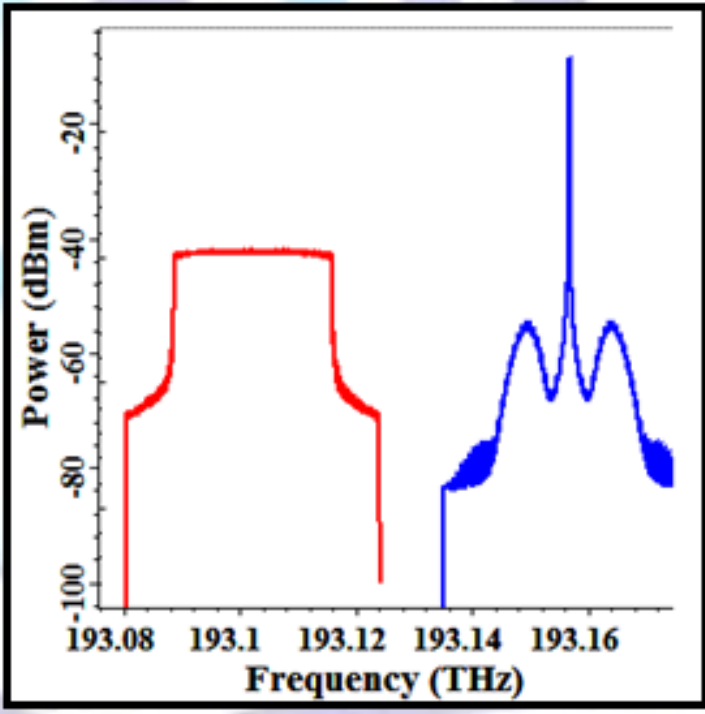

(d)

Fig. 5: Spectra of the optical multiplexed signals generated by combining CO-OFDM signal with one of the following UWB signal (a) monocycle OOK (b) monocycle BPM (c) $5^{\text {th }}$-order derivative Gaussian OOK (d) $5^{\text {th }}$ order derivative Gaussian BPM. 
Table 2 lists the BER for the four UWB signals after transmission over a single span with the CO-OFDM signal. The corresponding received eye diagrams of the IR-UWB signals are shown in Fig. 6. Results related to BERs corresponding to the transmission of UWB signals alone over the fiber are also given in the table. These results are used to calculate Figure of Degradation (FoD)

$$
F o D(d B)=\log \left(B E R_{W}\right)-\log \left(B E R_{0}\right)
$$

(2)

where $B E R_{W}$ corresponds to the BER of the UWB signal when OFDM signal is present.

Note that $B E R_{n}=1$ (i.e., FoD $=0$ ) indicates that the WDM system introduces no power penalty compared with the singlechannel system. Further, $B E R_{n}>1$ (i.e., $F o D>0$ ) indicates that the performance of the received channel in WDM system is degraded compared with the single-channel system.

Table 2: BER performance of IR-UWB signals after transmission over $96 \mathrm{~km}$ link (one span) with a singlechannel OFDM signal.

\begin{tabular}{|c|c|c|c|c|}
\hline \multirow[b]{2}{*}{ Pulse type } & \multirow{2}{*}{$\begin{array}{l}\text { Modulation } \\
\text { formats }\end{array}$} & \multicolumn{3}{|c|}{ BER } \\
\hline & & $\begin{array}{c}\text { Without } \\
\text { CO-OFDM }\end{array}$ & $\begin{array}{c}\text { With } \\
\text { CO-OFDM }\end{array}$ & FoD \\
\hline \multirow{2}{*}{ Monocycle } & OOK & $2.3 \times 10^{-9}$ & $2.7 \times 10^{-9}$ & 0.07 \\
\hline & BPM & $1.7 \times 10^{-23}$ & $6.5 \times 10^{-22}$ & 1.6 \\
\hline \multirow{2}{*}{$\begin{array}{c}5^{\text {th }} \text {-order } \\
\text { Derivative } \\
\text { Gaussian }\end{array}$} & OOK & $6.1 \times 10^{-5}$ & $7.1 \times 10^{-5}$ & 0.06 \\
\hline & BPM & $1.0 \times 10^{-13}$ & $1.2 \times 10^{-13}$ & 0.08 \\
\hline
\end{tabular}

The results in Table 2 highlight the following fact: the performance of the UWB system is slightly degraded in the presence of CO-OFDM transmission and the degradation is more pronounced for monocycle BPM signaling. The FoD for this case is 1.6 compared with $0.06-0.08$ for other UWB formats. It is worth to mention here that the BER of the OFDM system is not affected by the presence of any type of IR-UWB signals and equals to $6.2 \times 10^{-19}$ after transmission over one fiber span.

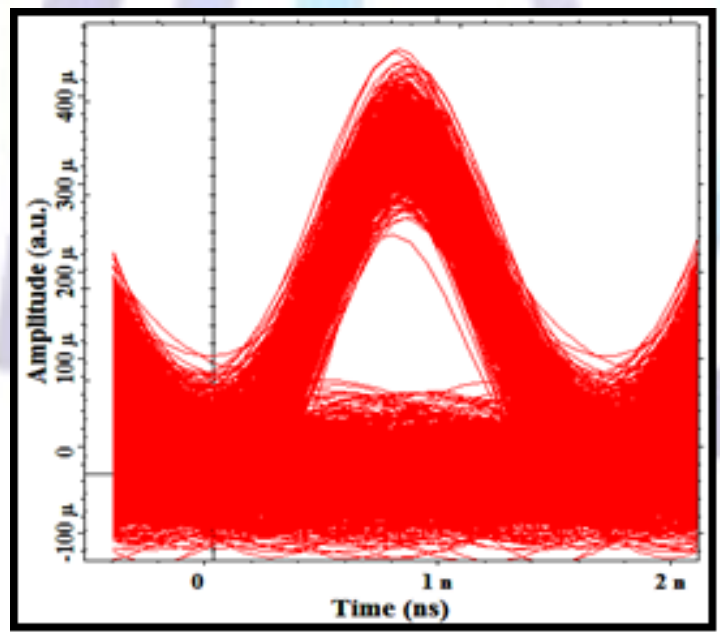

(a)

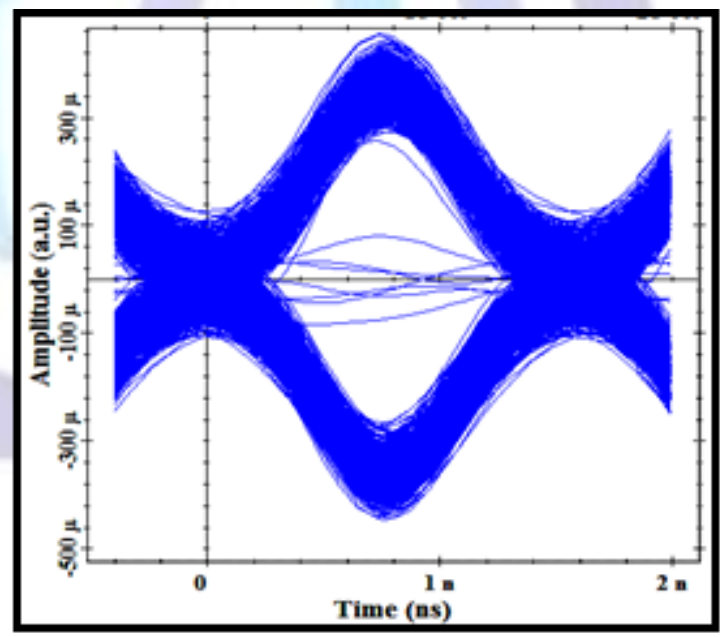

(b)

Fig. 6: Eye diagrams of the received IR-UWB signals after transmission over one span in WDM system incorporating optical CO-OFDM signal for (a) monocycle OOK (b) monocycle BPM (c) $5^{\text {th }}$-order derivative Gaussian OOK (d) $5^{\text {th }}$-order derivative Gaussian BPM. 


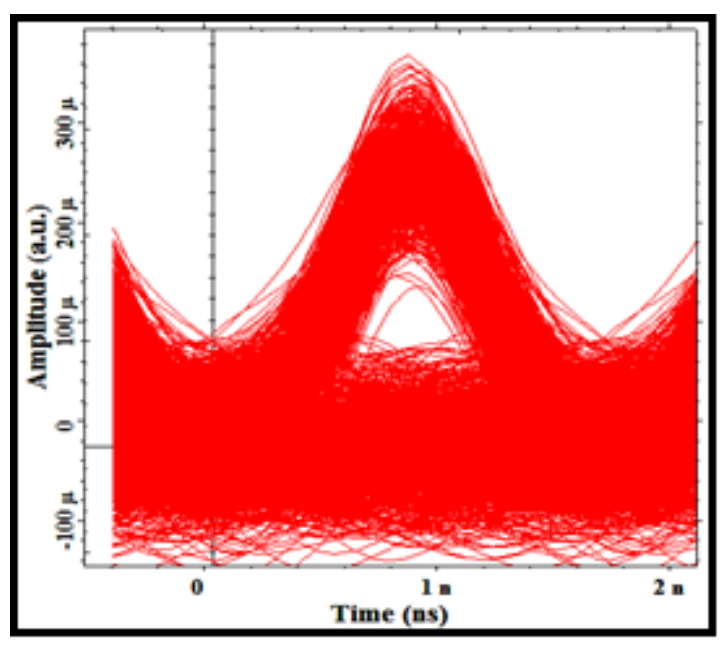

(c)

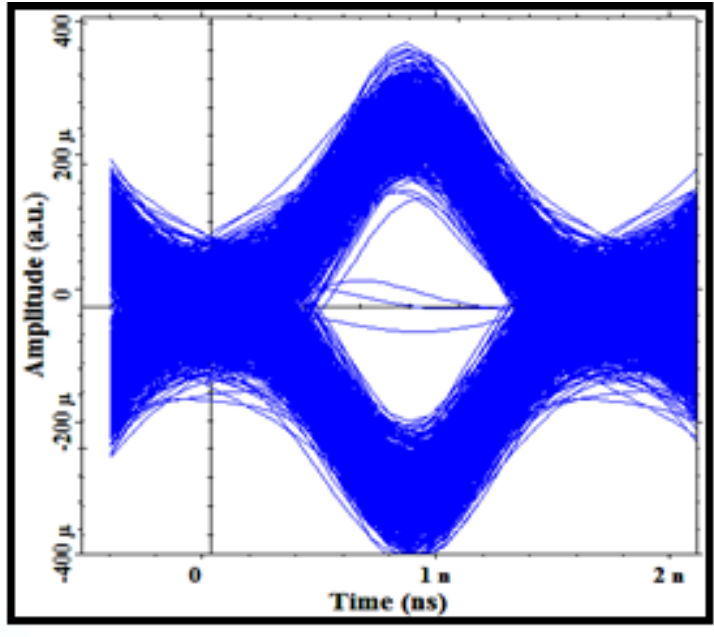

(d)

Fig. 6: (Continued).

\section{4- Transmission of IR-UWB Signals with Three-Channel CO-OFDM System}

The simulation performance in section 2-1 is repeated here for WDM system incorporating an UWB signal and threechannel CO-OFDM signal. A $50 \mathrm{GHz}$ channel spacing is used here with $\lambda_{\text {OFDM1 }}=1552.524 \mathrm{~nm}(193.1$ THz $), \lambda_{\text {OFDM2 }}=$ $1552.122 \mathrm{~nm}(193.15 \mathrm{THz}), \lambda_{\mathrm{OFDM} 3}=1551.720 \mathrm{~nm}(193.2 \mathrm{THz})$ and $\lambda_{\mathrm{UWB}}=1551.319 \mathrm{~nm}(193.25 \mathrm{THz})$.

The spectrum of the multiplexed signal corresponding to the transmission of the monocycle OOK signal with the threechannel optical OFDM is depicted in Fig. 7.

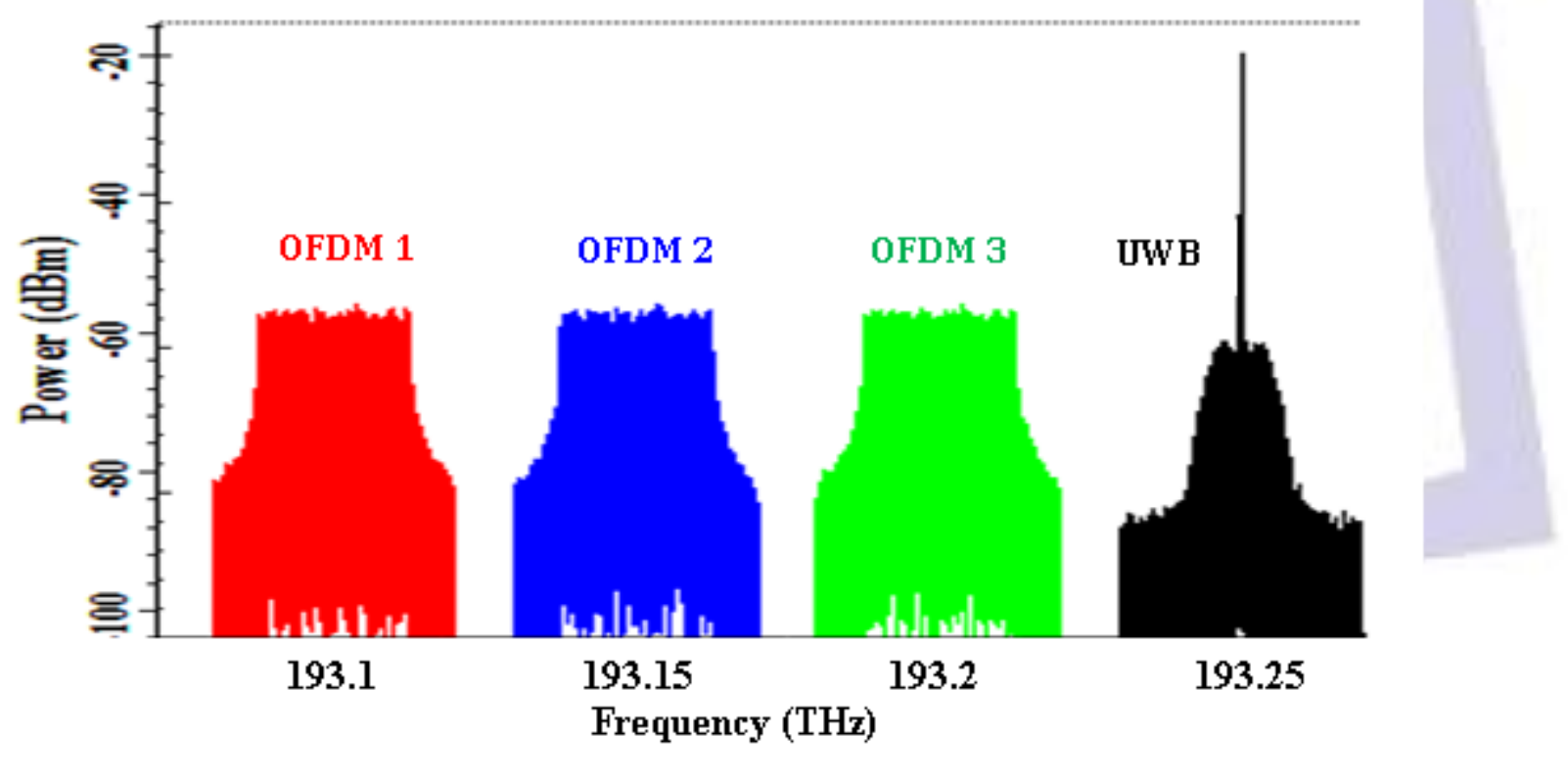

Fig. 7: Spectrum of the multiplexed signal generated by combining the monocycle OOK signal with three-channel CO-OFDM system.

Table 3 illustrates the effect of the presence of the OFDM signals on the performance of the transmitted UWB signals. Note that the performance degradation of the transmitted UWB signal increases in the presence of three optical OFDM signals compared to the case with one OFDM signal and this effect is more pronounce for the monocycle OOK signaling. 
Table 3: BER performance of UWB signals after transmission over 96 km link with three-channel Co-OFDM signal.

\begin{tabular}{c|c|c|c|c}
\hline \hline \multirow{2}{*}{ Pulse type } & $\begin{array}{c}\text { Modulation } \\
\text { formats }\end{array}$ & $\begin{array}{c}\text { Without CO- } \\
\text { OFDM }\end{array}$ & $\begin{array}{c}\text { With } \\
\text { CO-OFDM }\end{array}$ & FoD \\
\cline { 3 - 5 } & OOK & $2.3 \times 10^{-9}$ & $5.9 \times 10^{-9}$ & 1.3 \\
\hline \hline \multirow{2}{*}{ Monocycle } & BPM & $1.7 \times 10^{-23}$ & $3.3 \times 10^{-23}$ & 0.3 \\
\cline { 2 - 5 } & OOK & $6.1 \times 10^{-5}$ & $7.5 \times 10^{-5}$ & 0.09 \\
\hline $\begin{array}{c}\mathbf{5}^{\text {th}} \text {-order } \\
\text { Gerivative }\end{array}$ & BPM & $1.0 \times 10^{-13}$ & $3.1 \times 10^{-13}$ & 0.5 \\
\cline { 2 - 5 } & & & & \\
\hline
\end{tabular}

It is worth to mention here that the presence of the UWB signal will not affect the performance of the three OFDM channels as shown in Fig. 8. The BER of each OFDM channel is $6.2 \times 10^{-19}$ after one span transmission in the presence or absence of UWB signals.

\section{Total length (km)}

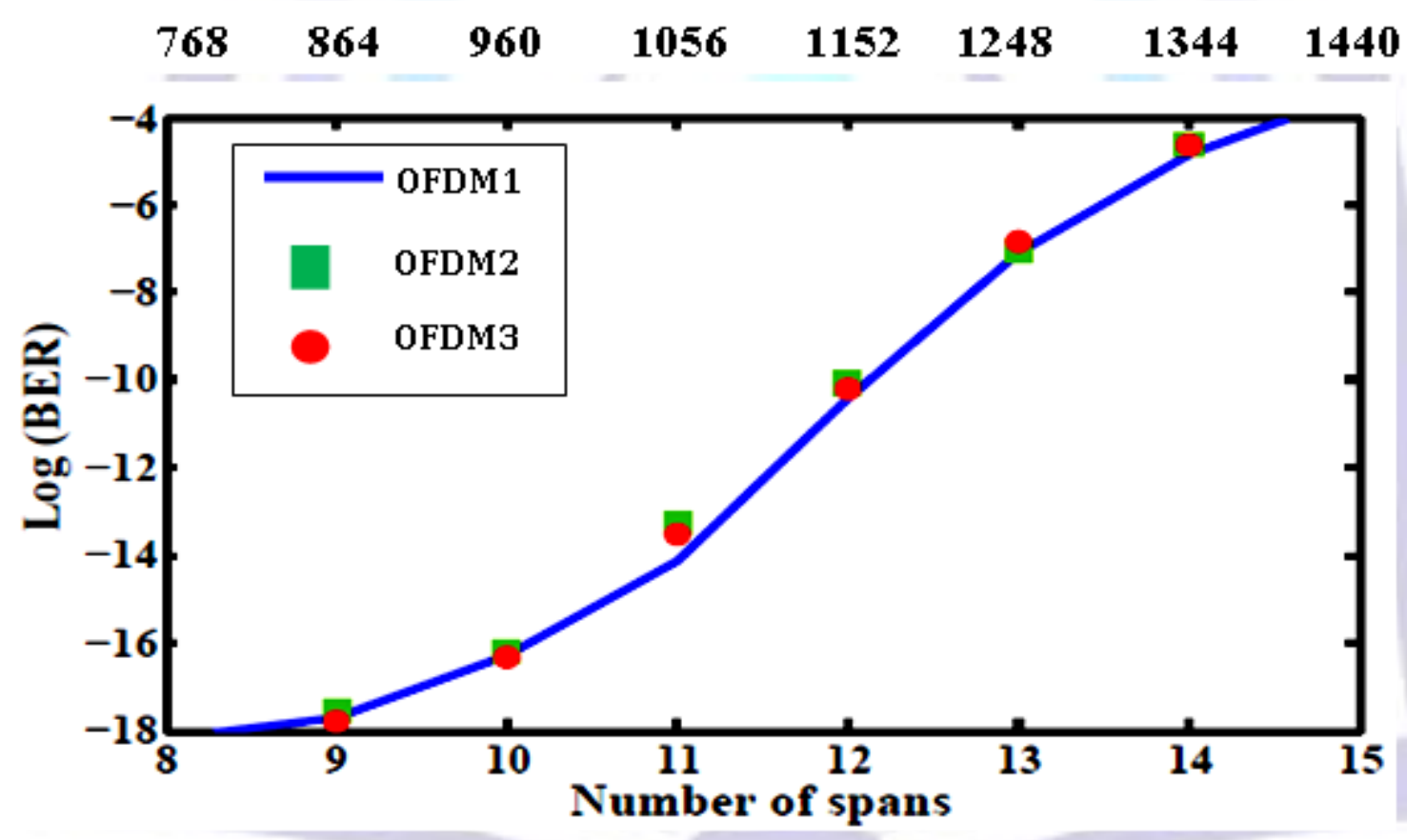

Fig. 8: BER as a function of number of spans and total link length for the three OFDM channels in IR-UWB/OFDM WDM system. 


\section{5- CONCLUSIONS}

A feasibility study for integrating IR-UWB wireless services into implemented CO-OFDM network has been investigated. Simulation results have been reported for transmitting $625 \mathrm{Mb} / \mathrm{s}$ Gaussian monocycle and $5^{\text {th }}$-order derivative Gaussian UWB signals with either single or three-channel CO-OFDM signals (50 Gb/s per channel). The simulation results reveal that the performance of the UWB signals is slightly degraded in the presence of OFDM signals and this effect is more pronounced as the number of OFDM channels increases. In contrast, the performance of the CO-OFDM channels is not affected by the presence of the wireless services.

\section{6- REFERENCES}

[1] S. T. Abraha, C. Okonkwo, H. Yang, D. Visani, Y. Shi, H. D. Jung, E. Tangdiongga, and T. Koonen, "Performance evaluation of IR-UWB in short-range fiber communication using linear combination of monocycles," Journal of Lightwave Technology, Vol. 29, No. 8, PP. 1143-1151, APRIL, 2011.

[2] H. Feng, M. P. Fok, S. Xiao, J. Ge, Q. Zhou, M. Locke,R. Toole, and W. Hu1, "A Reconfigurable high-order UWB signal generation scheme using RSOA-MZI structure," IEEE Photonics Journal, Vol. 6, No. 2, PP. $7900307-$ 7900307, April, 2014.

[3] P. Li, H. Chen, M. Chen, and S. Xie, "Gigabit/s photonic generation, modulation, and transmission for a reconfigurable impulse radio UWB over fiber system," IEEE Photonics Journal, Vol. 4, No. 3, PP. 805-816, June, 2012.

[4] P. Li, H. Chen, X. Wang, H. Yu, M. Chen, and S. Xie, "Photonic generation and transmission of 2-Gbit/s powerefficient IR-UWB signals employing an electro-optic phase modulator, "IEEE Photonics Technology Letters, Vol. 25, No. 2, PP. 144-146, January, 2013.

[5] X. Yu, T. B. Gibbon, R. Rodes, T. T. Pham, and I. T. Monroy, "System wide implementation of photonically generated impulse radio ultra-wideband for gigabit fiber-wireless access," Journal of Lightwave Technology, Vol. 31, No. 2, PP. 264-275, January, 2013.

[6] T. T. Pham, X. Yu, T. B. Gibbon, L. Dittmann, and I.T. Monroy," A WDM-PON-compatible system for simultaneous distribution of gigabit baseband and wireless ultrawideband services with flexible bandwidth allocation," IEEE Photonics Journal, Vol. 3, No. 1, PP. 13-19, February, 2011.

[7] K. Miyamoto, T. Tashiro, Y. Fukada, J. I. Kani, J. Terada, N. Yoshimoto, T. Iwakuni, T. Higashino, K. Tsukamoto, S. Komaki, and K. Iwatsuki, "Transmission performance investigation of RF signal in RoF-DAS over WDM-PON with bandpass-sampling and optical TDM," Journal of Lightwave Technology, Vol. 31, No. 22, PP. 3477-3488, November, 2013.

[8] S. Pan, and J. Yao, "IR-UWB-over-fiber systems compatible with WDM-PON networks," Journal of Lightwave Technology, Vol. 29, No. 20, PP. 3025-3034, October, 2011.

[9] S. Zhang, Y. Zhang, M. F. Huang, F. Yaman, E. Mateo, D. Qian, L. Xu, Y. Shao, and I. B. Djordjevic, "Transoceanic transmission of $40117.6 \mathrm{~Gb} / \mathrm{s}$ PDM-OFDM-16QAM over hybrid large-core/ultralow-loss fiber," Journal of Lightwave Technology, Vol. 31, No. 4, PP. 498-505, February, 2013.

[10] L. Yan, A. E. Willner, X. Wu, A. Yi, A. Bogoni, Z. Y. Chen, and H. Y. Jiang, "All-optical signal processing for ultrahigh speed optical systems and networks," Journal of Lightwave Technology, Vol. 30, No. 24, PP. 37603770, December, 2012.

[11] M. Bolea, R. P. Giddings, and J. M. Tang, "Digital orthogonal filter-enabled optical OFDM channel multiplexing for software-reconfigurable elastic PONs," Journal of Lightwave Technology, Vol. 32, No. 6, PP. 1200-1206, MARCH, 2014.

[12] M. C. Cheng, C. T. Tsai, Y. C. Chi, and G. R. Lin, "Direct QAM-OFDM encoding of an L-band master-to-slave injection-locked WRC-FPLD pair for $28 \times 20 \mathrm{~Gb} / \mathrm{s}$ DWDM-PON transmission," Journal of Lightwave Technology, Vol. 32, No. 17, PP. 2981-2988, September , 2014.

[13] J. Schr"oder, L. B. Du, J. Carpenter, B. J. Eggleton, and A. J. Lowery, "All-optical OFDM with cyclic prefix insertion using flexible wavelength selective switch optical processing," Journal of Lightwave Technology, Vol. 32, No. 4, PP. 752-759, February, 2014.

[14] S. Cao, C. Yu, and P. Yu. Kam, "A performance investigation of correlationbased and pilot-tone-assisted frequency offset compensation method for CO-OFDM," Optics Express, Vol. 21, No. 19, PP. 22847- 22853, September, 2013.

[15] M. H. Shoreh, "Compensation of nonlinearity impairments in coherent optical OFDM systems using multiple optical phase conjugate modules," Journal of Optical Communication Networks, Vol. 6, No. 6, PP. 549-558, June, 2014.

[16] S. T. Le, K. J. Blow, V. K. Mezentsev, and S. K. Turitsyn, "Bit error rate estimation methods for QPSK CO-OFDM transmission," Journal of Lightwave Technology, Vol. 32, No. 17, PP. 2951-2959, September, 2014. 


\section{Author Biography}

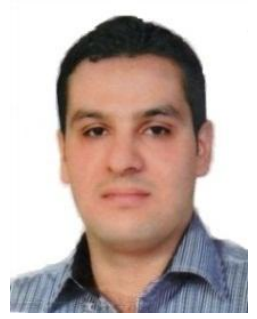

Jaffar Emad Kadum was born in Baghdad, Iraq, in 1986. He received the B.Sc. degree in Electronic and Communications Engineering from Alnahrain University, Iraq, in 2008. Currently, he is working toward the M.Sc. degree in Electronic and Communications Engineering at Alnahrain University. His research interests include ultra wideband over fiber, radio over fiber, microwave photonics and Optical communications systems.

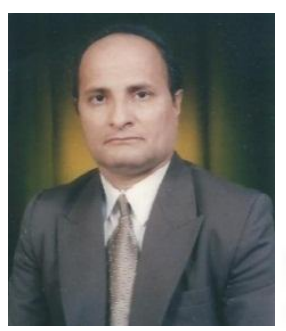

Raad Sami Fyath was born in Maysan, Iraq, in 1954. He received the B.Sc. degree in Electrical Engineering from the University of Basrah, Iraq, in 1976, the M.Sc. degree in Electronics and Communications Engineering from the University of Baghdad, Iraq, in 1987, and the PhD degree in Electronics Engineering from University of Wales-Bangor, UK, in 1990. Currently, he is a professor of electronics and communications engineering at the College of Engineering, Alnahrain University, Baghdad, Iraq. His research interests include Optical and wireless communications, Optoelectronics, and Nanophotonics. He published more than 100 papers in different scientific journals and conference proceedings.

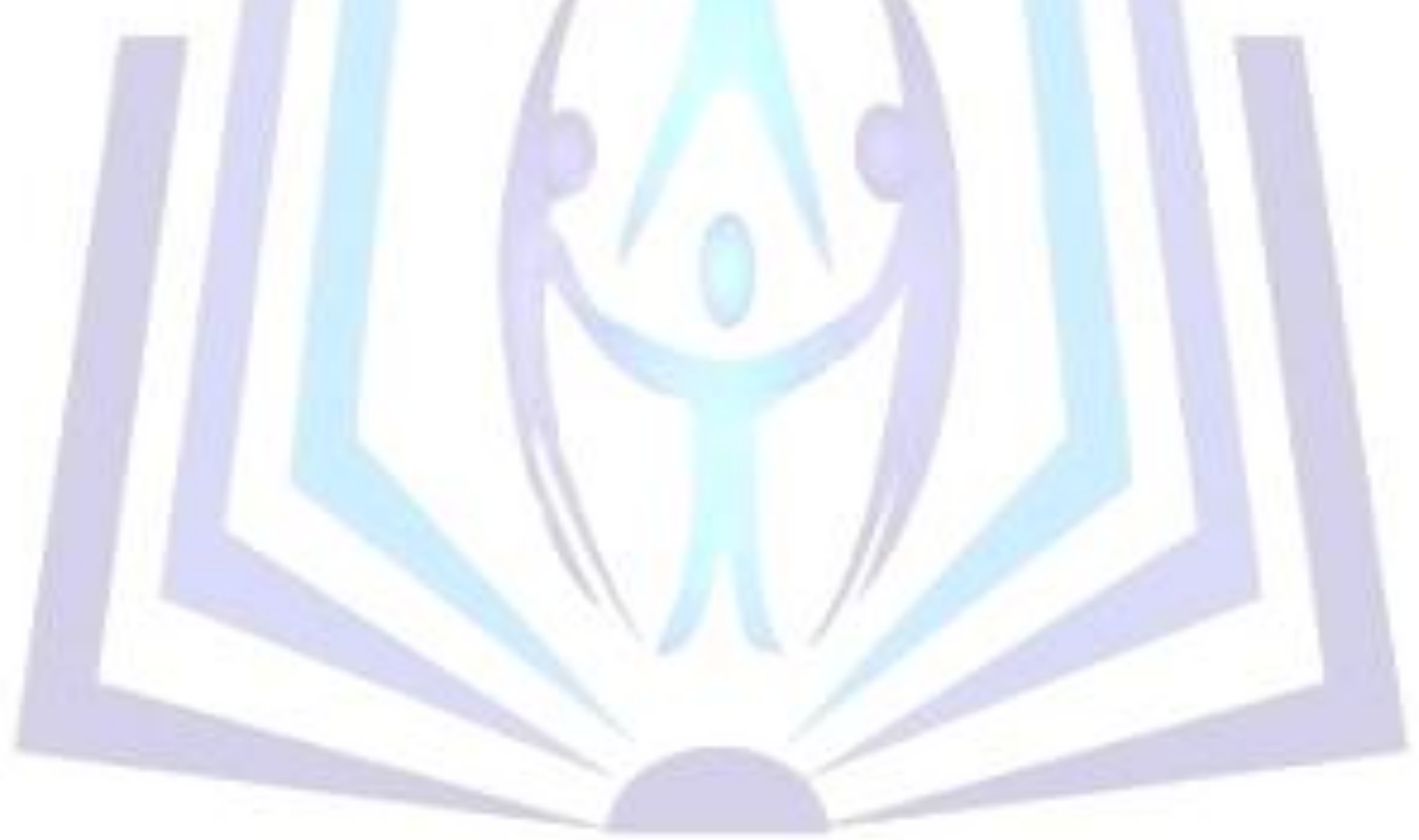

